\title{
Displacement across the Trecastagni Fault (Mt. Etna) and induced seismicity: the October 2009 to January 2010 episode
}

\author{
Salvatore Gambino ${ }^{1,}$, Alessandro Bonforte ${ }^{1}$, Antonino Carnazzo ${ }^{2}$, Giuseppe Falzone ${ }^{1}$, Ferruccio Ferrari ${ }^{1}$, \\ Angelo Ferro ${ }^{1}$, Francesco Guglielmino ${ }^{1}$, Giuseppe Laudani ${ }^{1}$, Vincenza Maiolino ${ }^{1}$, Giuseppe Puglisi ${ }^{1}$
}

\author{
1 Istituto Nazionale di Geofisica e Vulcanologia, Sezione di Catania, Catania, Italy \\ 2 Provincia Regionale di Catania, Tremestieri Etneo (Catania), Italy
}

\author{
Article history \\ Received September 23, 2010; accepted June 16, 2011. \\ Subject classification: \\ Measurements and monitoring, Crustal deformations, Volcano seismology, Wire extensometer, Shallow earthquakes, Fault dynamics.
}

\section{ABSTRACT}

The Trecastagni Fault (TF) is a NNW-SSE tectonic structure inside Mt. Etna that is characterized by evident morphological scarps and normal and right-lateral type movements that directly affect roads and buildings. The TF has an important role in the instability that affects the southeastern flank of Mt. Etna, and it represents part of the southern boundary of the unstable sector. Starting from 2005, the TF has been monitored using continuous wire extensometers and by carrying out periodic direct measurements across the northern and central sectors. From 2005 to September 2009, the measurements show that the TF has undergone continuous extension of about 2-3 mm/yr. During the October 2009 to January 2010 period, the creep rate of the TF reached up to 5.5 to 7.0 $\mathrm{mm} / \mathrm{yr}$, and this was accompanied by several shallow, low magnitude earthquakes that were felt by local people. This episode appears to be linked to the increase in the sliding velocity of the eastern flank that occurred during 2009.

\section{Introduction}

The geodynamic framework of Mt. Etna is characterized by a compressive stress regime, which trends roughly N-S, and is due to the collision of the Eurasia and Africa plates, and an extensional regime that trends roughly E-W.

The volcano edifice has formed at the intersection of two regional fault systems, with NNW-SSE and NE-SW trends (Figure 1). The complex interaction between regional stress, gravity force and dyke-induced rifting has produced the slow sliding of the eastern and south-eastern flanks of the volcano (flank dynamics), the main evidence for which is the many fault systems that have cropped out in this area, the frequent seismic activity, and the intense ground deformations. The flank dynamics at Mt. Etna appear to have an important role as a 'trigger' for the volcanic activity [e.g. Allard et al. 2006, Bonforte et al. 2007, Bonforte et al. 2008]. In this context, the Pernicana-Provenzana Fault System is unanimously indicated as the northern boundary of the eastern sliding flank, as any evidence of the flank dynamics abruptly disappears northward of this important feature. The south-eastern boundary is less defined, because all the evidence gradually diminishes [e.g. Borgia et al. 1992, Lo Giudice and Rasa 1992, Froger et al. 2001]: the deformations gradually decrease south-westward; the seismicity becomes shallower and/or less intense; and the fault systems are less continuous and/or evident. Among the different faults involved in the south-eastern boundary, from $\mathrm{W}$ to $\mathrm{E}$ there are the Ragalna Fault system [Neri et al. 2007], the Mascalucia-Tremestieri Fault, and the TrecastagniTremestieri Fault (TF). These faults are characterized by evident morphological escarpments, which are sometimes masked by cones and lava.

Since 2005, the TF has been monitored using continuous wire extensometers and through periodic direct measurements across the discontinuity in the northern sector of the fault. This monitoring activity has shown an increase in the rate change in the fault displacement with respect to the relatively constant rate of displacement measured in previous years. This was accompanied by local seismicity, in October 2009.

This study provides details of the 2005 to 2010 TF displacements and seismicity, and discusses this behavior in the framework of the flank dynamics and volcanic activity of Mt. Etna.

\section{The Trecastagni Fault}

The TF is a discontinuity that has developed in the southern flank of Mt. Etna, between the villages of Trecastagni and San Giovanni la Punta. This is an active structure with an approximately NNW-SSE trend (Figure 1) that is characterized by morphological escarpments and very shallow seismicity. The effects of the activity of the TF 


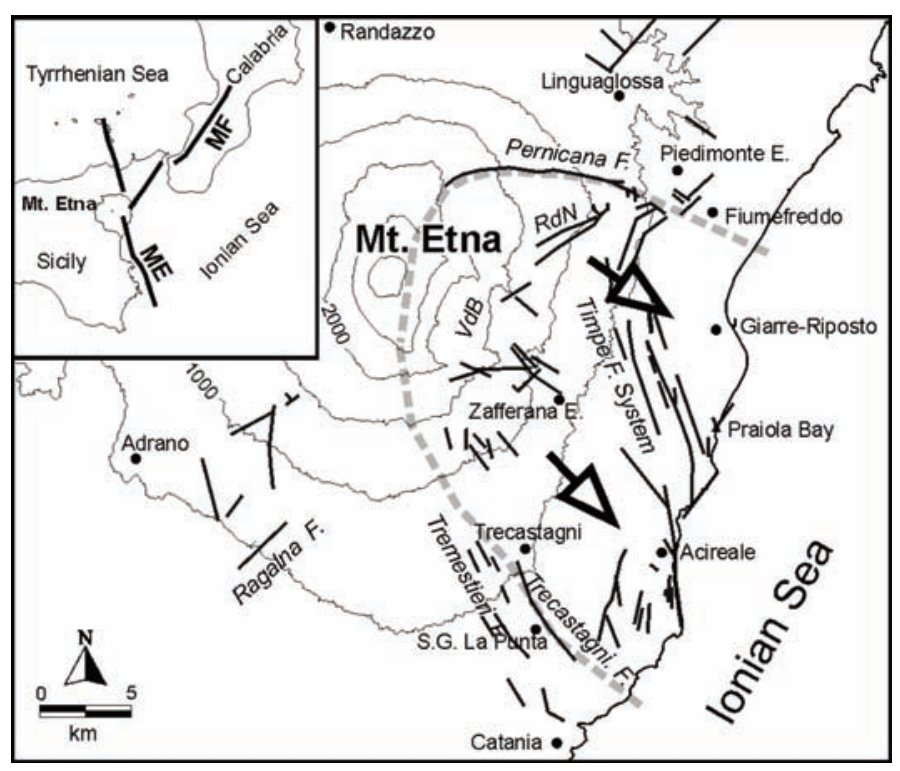

Figure 1. Surface-fault map of Mt. Etna. Inset: main regional fault systems: MF, Messina-Fiumefreddo line; ME, Malta Escarpment; RdN, Ripe della Naca; VdB, Valle del Bove. Gray line identifies the sliding sector.

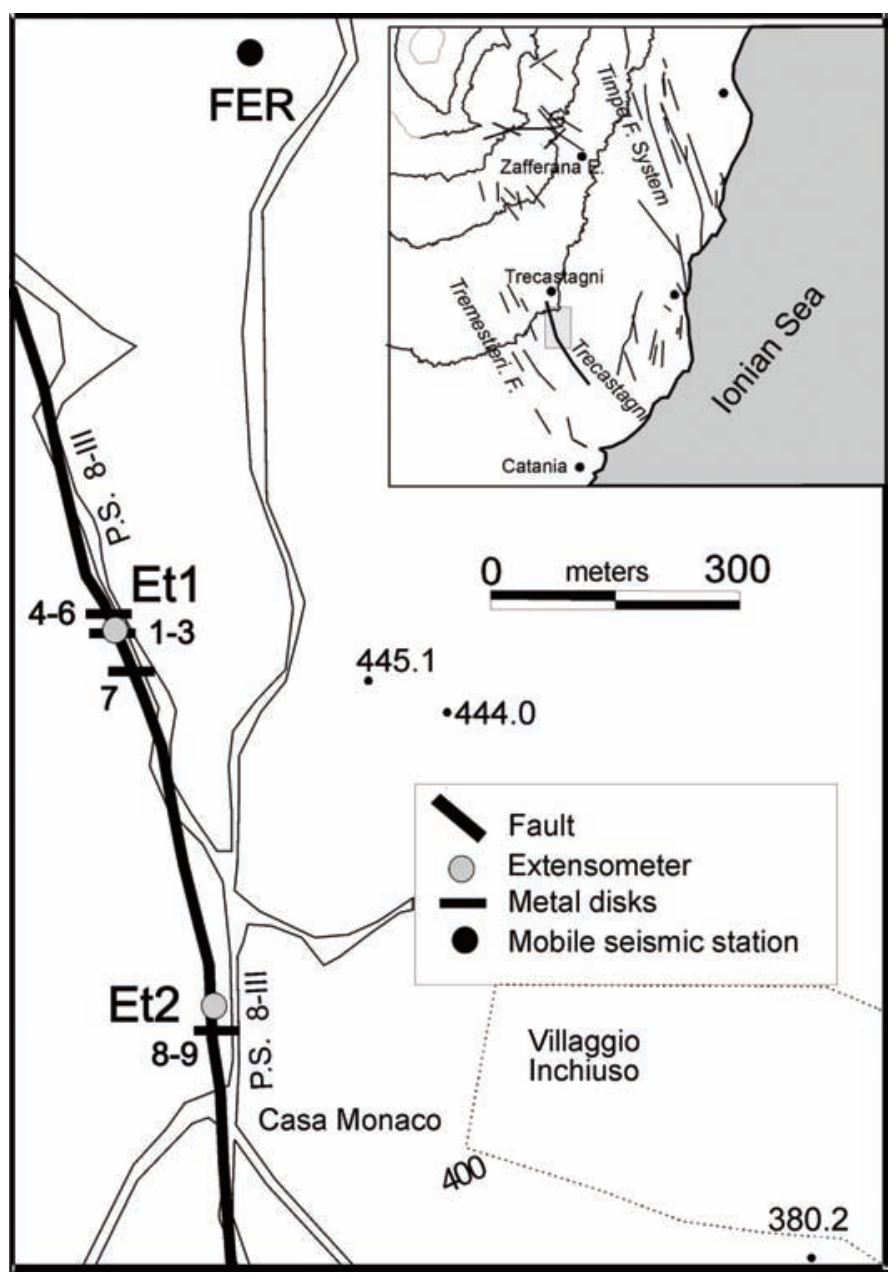

Figure 2. Location map of the extensometer stations Et1 and Et2, the discrete measurement sites, and the FER mobile seismic station. (creep) are visible on many stretches of provincial road 8-III (P.S. 8-III) (Figure 2).

The first studies on the dynamics of the TF were performed by Lo Giudice and Rasà [1992] and were based on the effects of the September 1980 seismic crisis. The seismicity of the TF is characterized by very shallow earthquakes with typical focal depths of 1-2 km. Evident coseismic surface faulting occurred along the fault scarp in September 1980 and in November 1988 [Azzaro 1999]. Hollows were seen to develop in agricultural land, along with fractures that offset buildings, boundary walls and the P.S. 8-III road, after the local shocks on September 16 and 20, 1980 , that displaced the northernmost and the central segments of the fault, as also seen after the November 21, 1988 earthquake [Azzaro 1999]. Three other similar episodes have been reconstructed for May 26, 1903, July 20, 1917, and February 17, 1955, through historical research [Azzaro and D'Amico 2008].

Data on deformations across the TF were relatively sporadic until 2005. In their analysis of interferometric synthetic aperture radar (InSAR) interferograms that covered the 1996 to January 1998 Mt. Etna inflation period, Froger et al. [2001] estimated a deformation rate of about 4-6 mm/yr, as measured along the line of sight of the satellite (in this case, with an incidence angle of about $23^{\circ}$ from WSW). Recent time series analyses of InSAR data from 1995 to 2000 using the permanent scatters techniques quantified a downthrow of the eastern side of the TF at a rate of about 4 $\mathrm{mm} / \mathrm{yr}$ and negligible E-W movement [Bonforte et al. 2011].

The big intrusion of July 2001 (the 2001 eruption) was very important in the recent dynamics of Mt. Etna [e.g. Bonforte et al. 2009], as in the months that followed it produced an acceleration of the deformations and seismic activity along the Ionian coast [Puglisi et al. 2008].

During the 2002 to $2003 \mathrm{Mt}$. Etna eruption, Neri et al. [2004] claimed to have measured displacements of more than $2 \mathrm{~cm}$ after a duration magnitude, $M_{d}, 2.6$ shallow earthquake that was recorded on November 26, 2002. This was interpreted as the migration of the ground deformation induced by the eruptive intrusion along the NE rift that first affected the Pernicana Fault.

Finally, using InSAR data, Solaro et al. [2010] obtained a velocity not exceeding $5 \mathrm{~mm} / \mathrm{yr}$ for the 2003 to 2008 period, similar to that of 1994 to 2000 .

\section{Network and data}

In 2005, the Istituto Nazionale di Geofisica e Vulcanologia and the Provincia di Catania began to implement a local monitoring system that was chiefly aimed at quantification of the creep phenomena across the provincial road, and thus to relate this to the current volcanic activity of Mt. Etna. At present, the monitoring of the TF consists of two continuous wire extensometers and a system 
for periodic direct measurements across the discontinuity in the central and north-central sectors of the fault (Figure 2).

\subsection{Extensometers}

Extensometers are common instruments that have been developed to continuously monitor ground displacements, such as with landslides and dams. They are also used to monitor active fault creep and fracture opening. Direct measurements of creep movement along faults and fractures have been applied along segments of the San Andreas Fault, California, USA [Bilham and Whitehead 1997], in Taiwan [Lee et al. 2000], and for Mt. Etna [Gambino 2004, Neri et al. 2004], Piton de la Fournaise, Réunion Island [Peltier et al. 2006] and Mt. St. Helens, Washington, USA [Iwatsubo et al. 1992].

We installed two continuous wire extensometers at the two stations of ET1 and ET2 (Figure 2). These consist of a stainless steel transducer box and a target assembly made with an eyebolt expansion anchor (Figure 3). The displacement transducer is housed in a stainless steel body that is mounted on a fixing plate for wall/floor installation. An invar rope forms the connection between the transducer and the target. Each instrument is equipped with a multichannel datalogger that is programmed for 48 data points/day sampling (1 sample every $30 \mathrm{~min}$ ) and that includes acquisition of the displacement and ground temperature. Temperature data are necessary to minimize the seasonal and daily thermal variations in distance measurements. These two stations measure the relative displacements perpendicular to the fracture (the extensional component).

Figure 4 reports the May 2005 to May 2010 data that was recorded at the ET1 continuous extensometer. These displacement data are characterized by low daily noise $(<0.1$ $\mathrm{mm})$. The seasonal variations of the signal correlated well with the temperature variations (Figure 4A). Figure 4B shows the filtered data that was obtained using a linear distance-temperature regression to minimize the wire-length variation $(\triangle A)$ due to temperature expansion:

$$
\Delta A=\lambda \Delta \mathrm{T} A O
$$

where $\lambda$ is the coefficient of linear expansion (for invar, $1.5 \times$ $\left.\times 10^{-6}{ }^{\circ} \mathrm{C}^{-1}\right), \Delta \mathrm{T}$ is the temperature variation, and $A o$ is the wire length.

The data recorded between May 2005 and September 2009 highlight an opening trend of about $2-3 \mathrm{~mm} / \mathrm{yr}$, with very slow variations around this value. However, from October 15, 2009, the data show a sharp increase in the trend that cumulated to more than $2 \mathrm{~mm}$ in the first 15 days, and to a total of $4 \mathrm{~mm}$ by the end of January 2010. From February 2010, the trend appeared to return to the same value measured before the October 2009 anomaly.

Several technical and environmental problems have prevented the obtaining of a continuous and reliable dataset for ET2. This station shows a signal that is poorly correlated to air temperature variations and is characterized by step displacement variations. Data recorded between June 2008 and April 2009 highlight a displacement of about $1 \mathrm{~mm}$. Afterwards, ET2 stopped data acquisition, and when it was restored on October 22, 2009, the sensor measured a variation of $4 \mathrm{~mm}$. From October 22, 2009, to the beginning of February 2010, the displacement was about $3 \mathrm{~mm}$, and from February 2010 the trend appeared to have returned to the same values measured before the October 2009 anomaly.

\subsection{Discrete measurements}

For the discrete measurements, we used an analog strain gauge (Model 58-C0230, Controls s.r.1.). Using appropriate metal discs fixed on both sides of a wall (Figure $5 \mathrm{~A}$ ), this instrument allows the determination of the linear changes

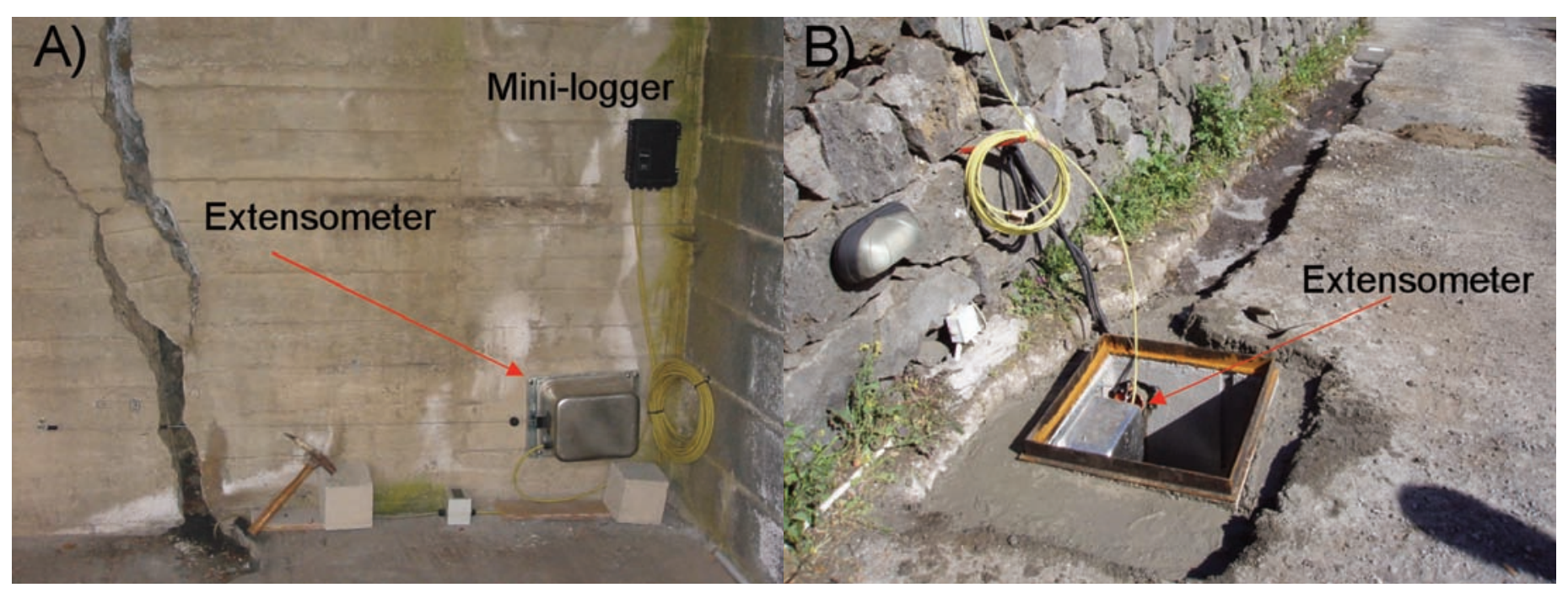

Figure 3. Photographs of the Et1 (A) and Et2 (B) extensometer sites during installation. 

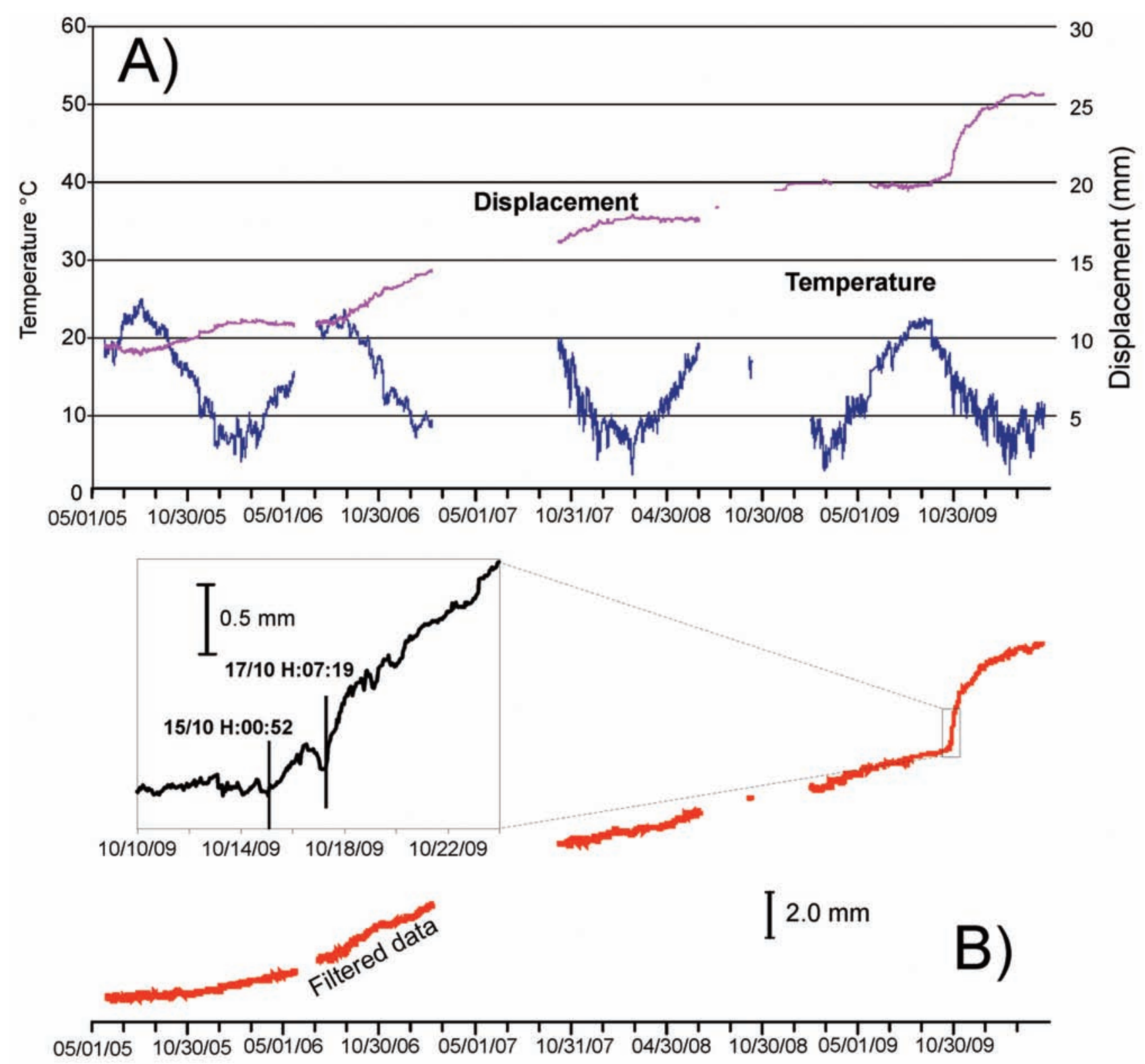

Figure 4. Distance trends and air temperatures (A) recorded at Et1 station, with the distance trends corrected for temperature effects (B), over the period from May 2005 to April 2010. Inset in (B): the time relationship between the displacements and the seismic events that occurred over the period of October $10-24,2010$. In coincidence with the beginning of the displacement anomaly, we recorded a $\mathrm{M}=2.1$ earthquake; two days later, a $\mathrm{M}=1.8$ earthquake occurred (17/10 H:07:19).

in the different positions of a discontinuity with the design precision of $0.001 \mathrm{~mm}$.

During 2005, we set up nine pairs of metal discs along several discontinuities related to the fault (Figure 5A). We measured the metal disc distances about three times per year. For the discrete measurements, the pairs of metal discs along the structure have been measured about 15 times since 2005 (Figure 5B).

During the period 2005 to September 2009, these measurements confirmed the results obtained by the continuous data, revealing the same behavior in the two different sectors monitored. The last two readings carried out on October 23, 2009, and March 25, 2010, confirm the increase in the displacement.

\section{Seismicity}

For Figure 6C,D, we selected the seismicity that occurred since May 2005 in a narrow area close to the TF. The earthquake map reports the best preliminary locations performed for surveillance purposes, which were obtained using Hypoellipse code [Lahr 1989] and a one-dimensional velocity crustal model derived from Hirn et al. [1991], with some minor modifications. The seismic activity recorded during the May 2005 to April 2010 period in this area comprises events located to a depth of $20 \mathrm{~km}$; Figure 6 reports the 34 events located within the first $5 \mathrm{~km}$ of depth that we consider as the only ones that might be related to the fault dynamics. Their magnitude is between 1.1 and 2.4. The seismicity is clustered in the northern part of the area, while 

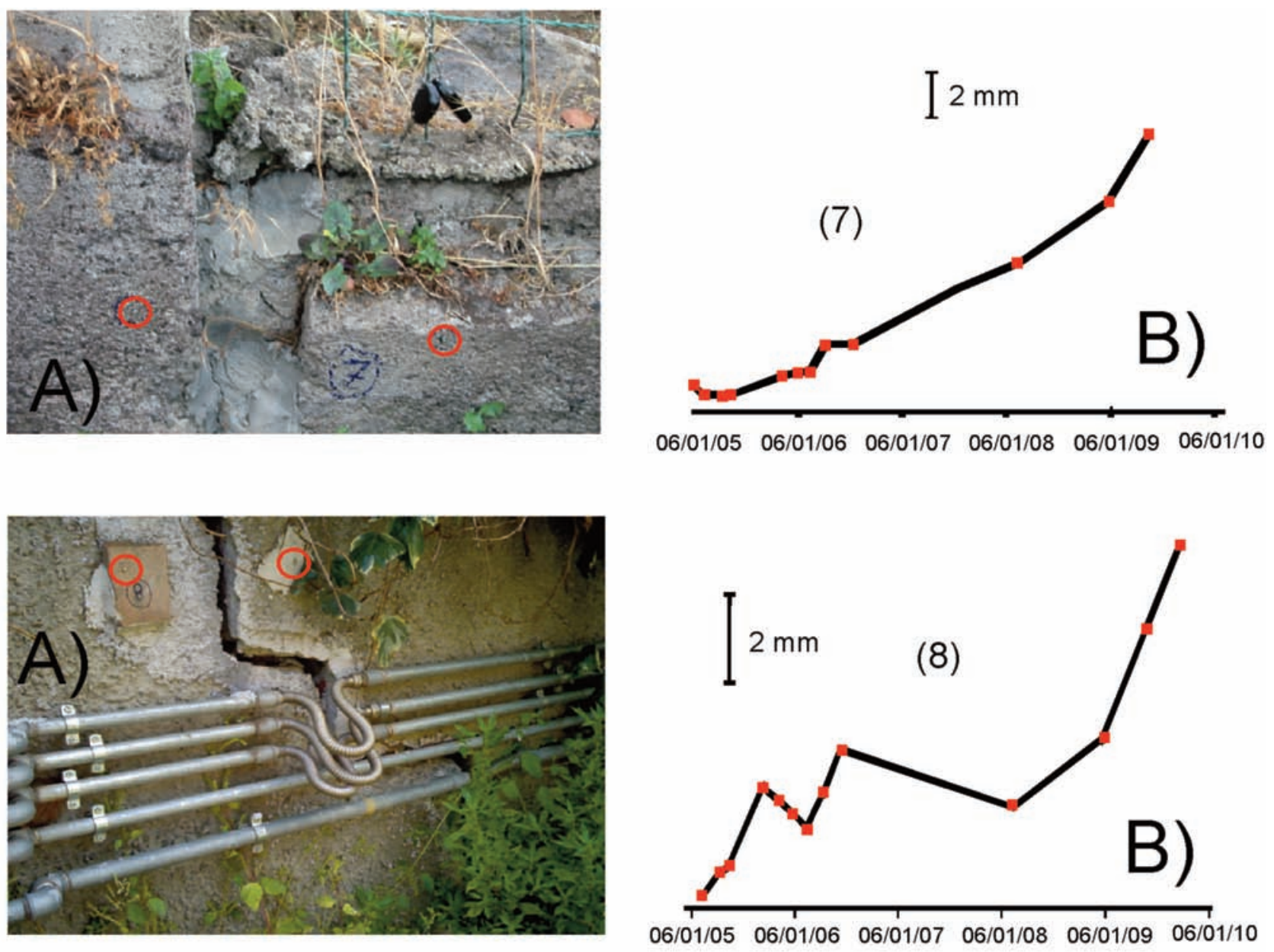

Figure 5. Photographs (A) and related data (B) of the $\mathrm{n}^{\circ} 7$ and $\mathrm{n}^{\circ} 8$ pairs of metal discs installed along the structure. Red circle evidence the metal discs. The graphs (B) indicates the changes in the distance between the metal discs.

it appears that no earthquakes occurred in the TF sector. However, we stress that the current configuration of the seismic network is not optimal for studying the seismicity of this area, as it is located outside of the Istituto Nazionale di Geofisica e Vulcanologia, Sezione di Catania, permanent seismic network, which consists of 40 seismic stations positioned all around the Mt. Etna volcano (Figure 6A). This situation might lead to shortfalls in the accuracy of hypocenter determinations and possible bias in epicenter positioning. However, it is still remarkable that an increase in seismicity in this sector occurred in the months that preceded the May 2008 eruption, and before the TF dynamic acceleration (Figure 7).

On October 15, 2009, at 00:52 a M=2.1 earthquake was distinctly felt by the resident population within a few kilometers along the central and northern TF area (Figure $6 \mathrm{D})$. This was a very shallow event that was characterized by waveforms with emergent onsets and low spectral content (Figure 6B), which suggested an extremely shallow hypocenter (latitude: 37.639; longitude: 15.063; depth: -0.73 $\mathrm{km}$ b.s.1.; horizontal error: $1.0 \mathrm{~km}$; vertical error: $1.2 \mathrm{~km}$; rms: 0.22; azimuthal gap: 190 degrees). The analytical location is reported in Figure 6C. However, we stress that the seismicity recorded in this area is extremely difficult to analyze because of the low magnitude events and the poor network coverage. Moreover, the velocity model of the entire volcanic edifice appears to be inadequate to represent the shallowest layer velocity of this area. For these reasons, no fault plane solutions are available for shallow events on the southeastern flank.

On October 20, 2009, we installed a mobile station (FER) equipped with local acquisition near the TF (Figure 2, Figure $6 \mathrm{C}$ ). In the following days, several micro-earthquakes were recorded at this FER station. For five of these events, we obtained the direction of the seismic ray from particle motion analysis (Figure 6E,F) and the distance from S-P time lapse (Figure 6D); these analyses suggest that the source area of the earthquake was the northern sector of the TF.

\section{Discussion and conclusions}

Previous studies that were performed by analyzing time series of InSAR data measured movement of the TF of the order of $4 \mathrm{~mm} / \mathrm{yr}$ from 1993 to 2008 (except the particular 2001 to 2003 period). This pattern of movement is in agreement with the spreading of the eastern flank towards the sea. Considering that field surveys show a right-lateral 

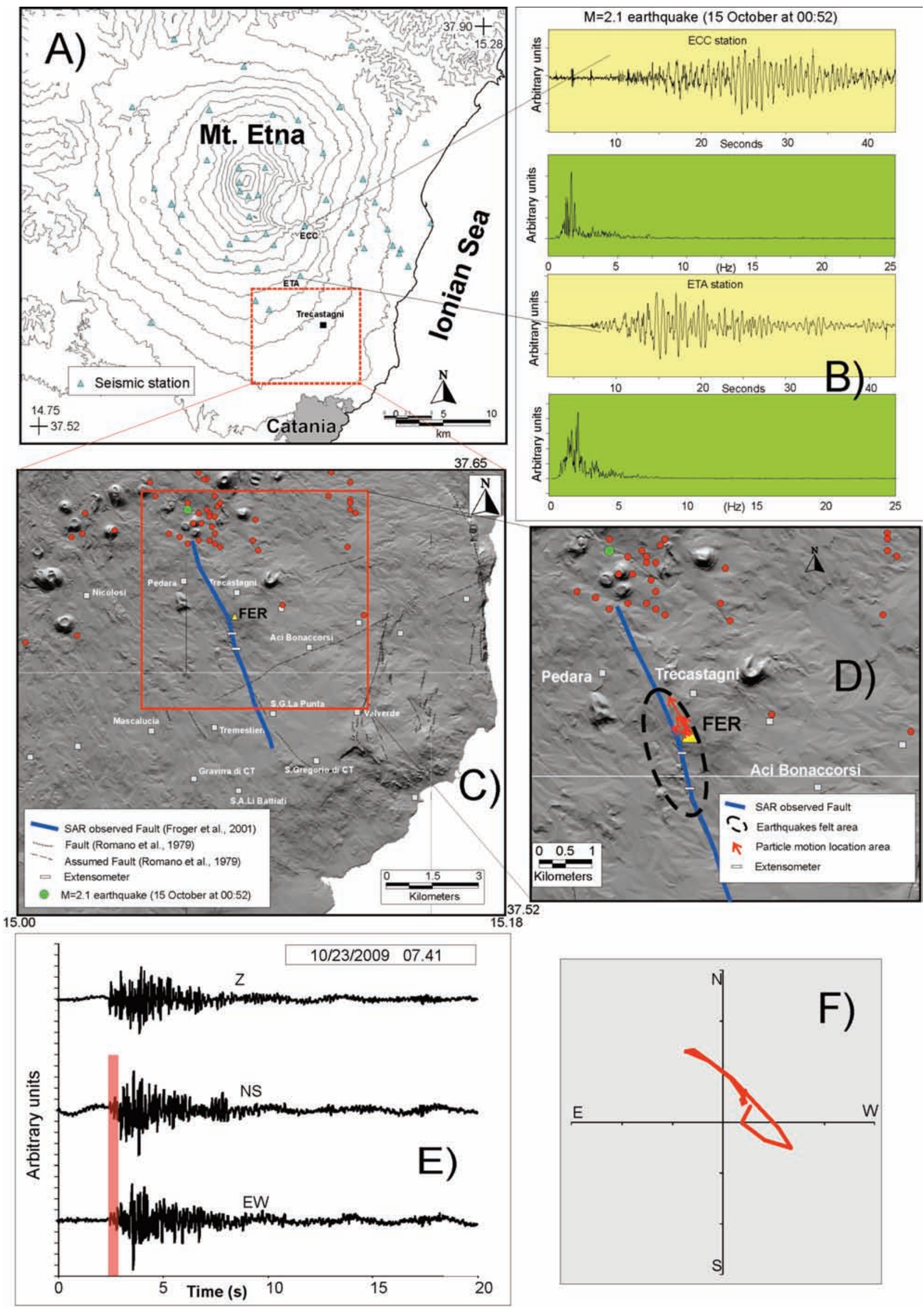

Figure 6. The Istituto Nazionale di Geofisica e Vulcanologia, Sezione di Catania, permanent seismic network (A; triangles), waveforms and spectra related to the October 15, 2009, 00:52 event recorded at the ECC (top panels) and ETA (lower panels) stations (B), seismicity recorded in the TF area between May 2005 and April 2010 (C, D), with microearthquake epicenters recorded at the FER station obtained from particle motion analysis and S-P seismic phase time lapse (D). Examples of waveform recorded at FER station (E); the red bar indicate the time window used for particle motion (F). 


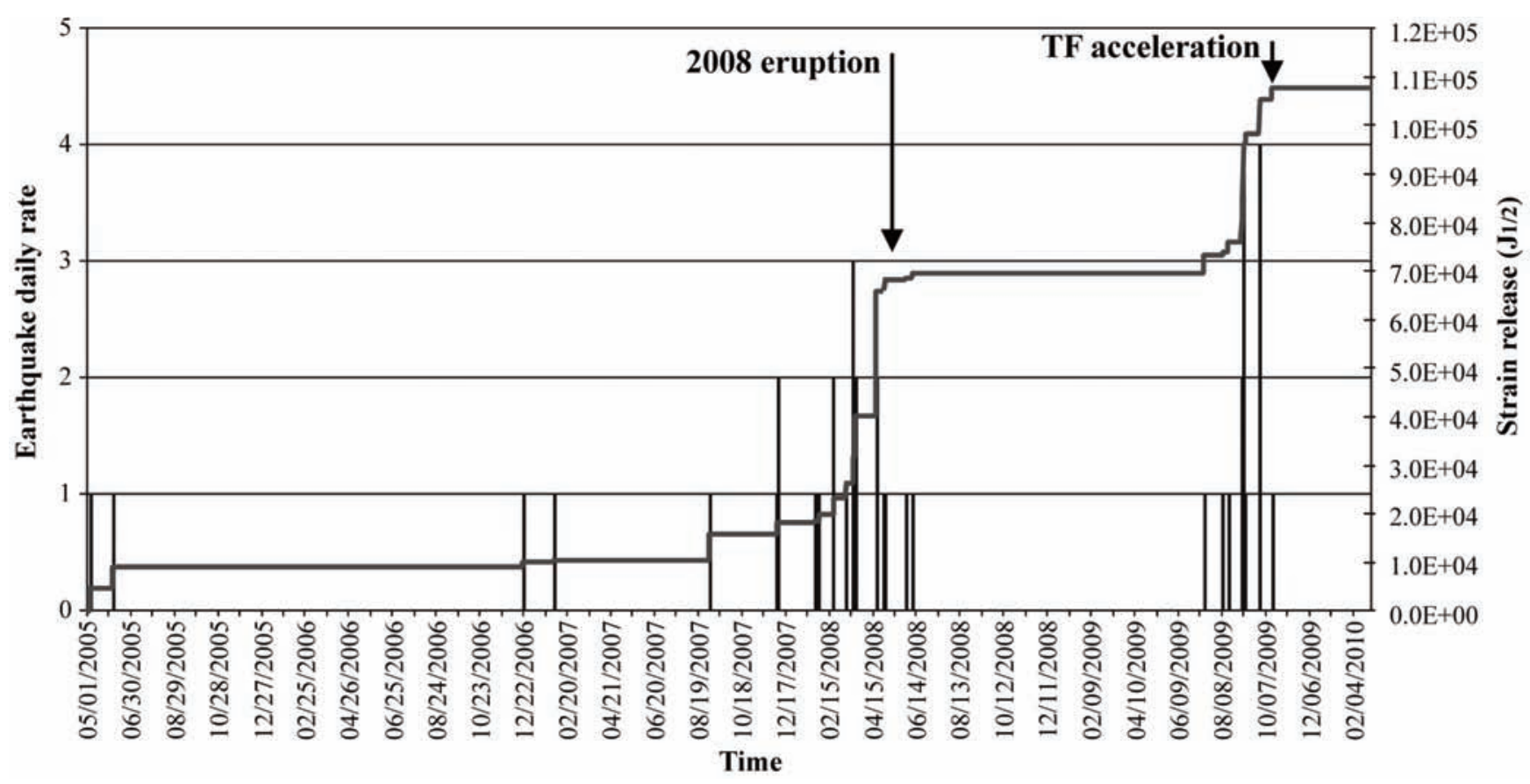

Figure 7. Earthquake daily rate and related strain release of the May 2005 to February 2010 seismicity that occurred in the narrow area reported in Figure 6D. The seismic strain release has been calculated as $\sqrt{E}$ with the following relationship [Richter 1958]: $\log E=9.9+1.9 \mathrm{M}_{d}-0.024 \mathrm{M}_{d}^{2}$, where $\mathrm{M}_{\mathrm{d}}$ is the duration magnitude.

component of the displacement and that the InSAR data cannot detect the N-S movements (thus preventing measurement of the complete movement across the fault), we can argue that the total displacement across the TF might be higher than $4 \mathrm{~mm} / \mathrm{yr}$.

The measurements with extensometers (both continuous and periodic) carried out across the TF since 2005 show that the fault was characterized by an average continuous displacement rate of about $2-3 \mathrm{~mm} / \mathrm{yr}$, until September 2009. This deformation rate is slightly lower than that measured by InSAR, and it raises the question of whether the deformations measured by extensometers are wholly representative of the total movements of a fault.

The InSAR results suggest that the discontinuity in the velocity maps is not so sharp and that the movement is distributed over an area of about a few hundred meters that crosses the TF. Thus, the fault where the extensometers are installed most likely represents one of the structural discontinuities involved in this movement. However, detailed studies are needed to provide a definitive answer to this question. Indeed, a local leveling network is currently being implemented across the TF [Bonforte et al. 2010].

On October 15, 2009, two important phenomena occurred at the TF: a $\mathrm{M}=2.1$ earthquake was recorded by the Istituto Nazionale di Geofisica e Vulcanologia seismic network at 00:52 GMT; and a simultaneous acceleration of the deformations was measured by the extensometers (Figure 4B). This was the beginning of a period that lasted 3 months that was characterized by high deformation rates across the TF and increased seismic release of this sector of the Mt. Etna volcano. The relevance of this phenomena and their simultaneity suggest a common origin that can be reasonably related to the eastward movement of the Mt. Etna south-eastern flank, due to the role of the TF in the structural assessment of the sliding flank of Mt. Etna [Bonforte et al. 2011].

All of the above discussions are directed towards a possible relationship between the deformation across the TF and the volcanic activity. Several authors have shown feedback processes between magmatic events and flank movement at Mt. Etna [e.g. Walter et al. 2005, Allard et al. 2006, Bonforte et al. 2008]. In particular, in studying the 2002 to 2003 period, Walter et al. [2005] used a three-dimensional numerical model to calculate stress changes related to shallow reservoir inflation, dyke intrusion and fault displacement, and this suggested three mechanisms of interaction at Mt. Etna:

The Eruption-Flank movement interaction. The feeding of magmatic reservoirs at depths of about 4-6 km results in the inflation of the volcano, which in turn, induces slips along the Pernicana Fault and the decollement at the base of the eastern flank (at about $5 \mathrm{~km}$ ).

The Flank movement-Eruption interaction. The flank movement induces the unclamping of the $\mathrm{NE}$ and $\mathrm{S}$ rift zones of Mt. Etna, which in turn produces a decompression of the magmatic system that favors the shallow intrusion.

The Fault-Fault interaction. Numerical modeling shows that the slip along the decollement, and the Pernicana and Santa Venerina Faults influence each other. 
Regarding the slip of the TF, Walter et al. [2005] stated that this might be encouraged by reservoir inflation, dyke intrusion and decollement slip. This means that any of the above-summarized mechanisms might have influenced the acceleration of the movement from October 15, 2009, to January 2010. In this context, we note that:

(i) After the end of the 2004 to 2005 eruption, the global positioning system (GPS) network recorded a renewal of the inflation that led to the July to December 2006 eruption [Bonforte et al. 2008]. This inflation did not encourage the TF slip (Figure 4); moreover, the 2007 to 2009 InSAR mean line-of-sight ascending velocity did not reveal any particular phases of inflation of the edifice (Figure 8);

(ii) In May 2008, an intrusive event led to the 2008 to 2009 eruption [Aloisi et al. 2009]; however, the magnitude of this event is not comparable with the 2002 episode that was analyzed by Walter et al. [2005]; moreover, it appears too far in time (17 months) to suggest any possible link [Solaro et al. 2010];

(iii) In March to May 2009, seismicity at the Pernicana and Moscarello Faults and ground deformations at low elevations testify to a sudden acceleration of the sliding of the eastern flank; GPS horizontal measurements (Figure 9) show an acceleration (from $1-2$ to $5-6 \mathrm{~cm} / \mathrm{yr}$ ) of the movements of the south-eastern flank between June 2008 and June 2009, in particular on the eastern points.

In light of the above, the TF increased displacements and induced seismicity that occurred from October 2009 to January 2010 would appear to be more linked to the acceleration of the eastern flank than to the other causes

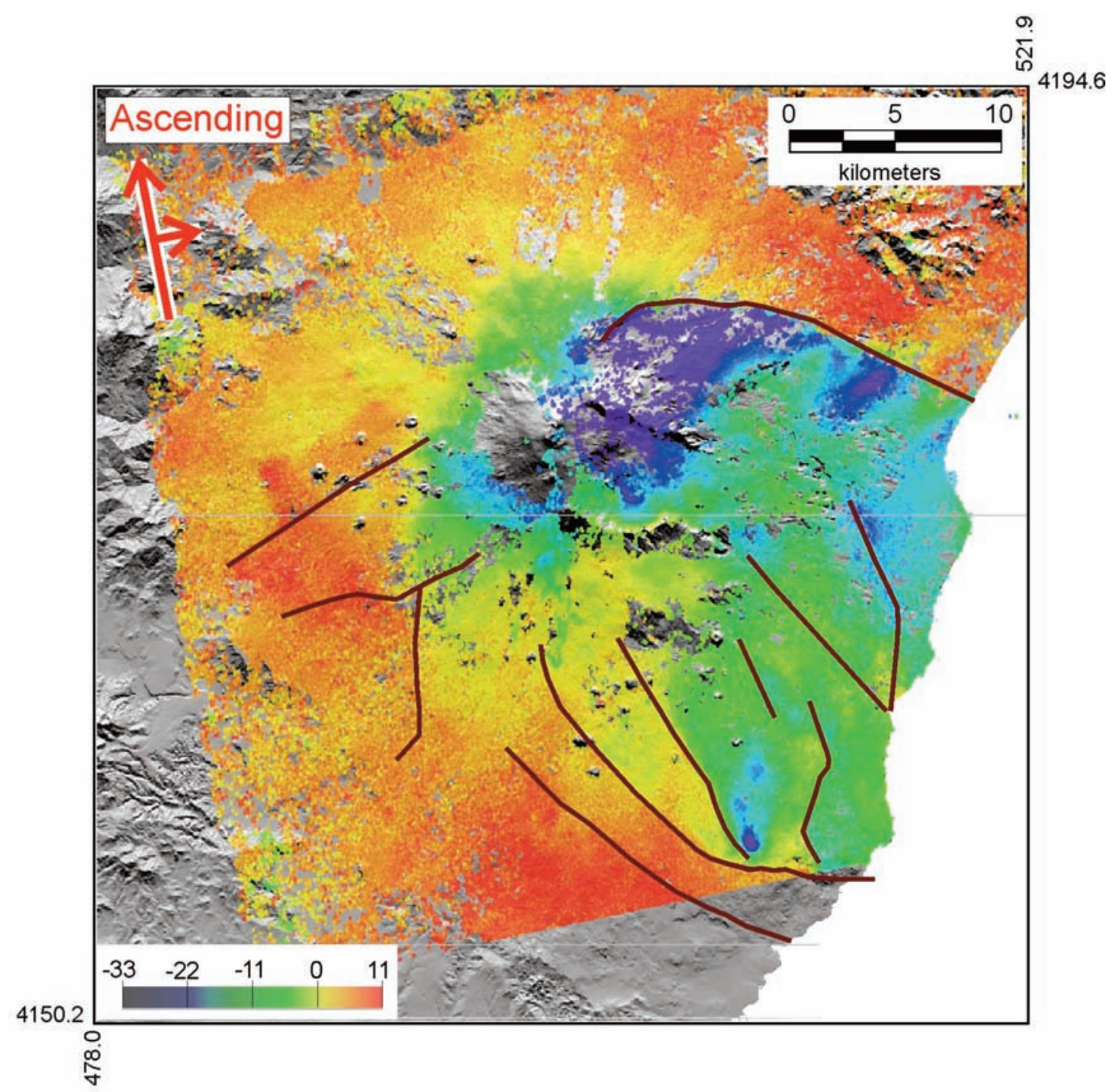

Figure 8. Mean ascending line-of-sight ground velocity ( $\mathrm{mm} / \mathrm{yr}$ ) referring to the 2007 to 2009 time span. The map was obtained using the persistent scatterer software, known as StaMPS / MTI [Hooper 2008], using all of the available ENVISAT ascending data that was acquired for Mt. Etna from January 2007 to October 2009. The main discontinuities in the permanent scatterers velocity field detected by Bonforte et al. [2011] are shown as brown line. Red arrows indicate the trajectory (from South to North) of the satellite and its look direction toward East. The colour scale is in $\mathrm{mm} / \mathrm{year}$. The bottom left and top right corner coordinates are in km (WGS84 Datum, UTM projection, zone 33 north). 


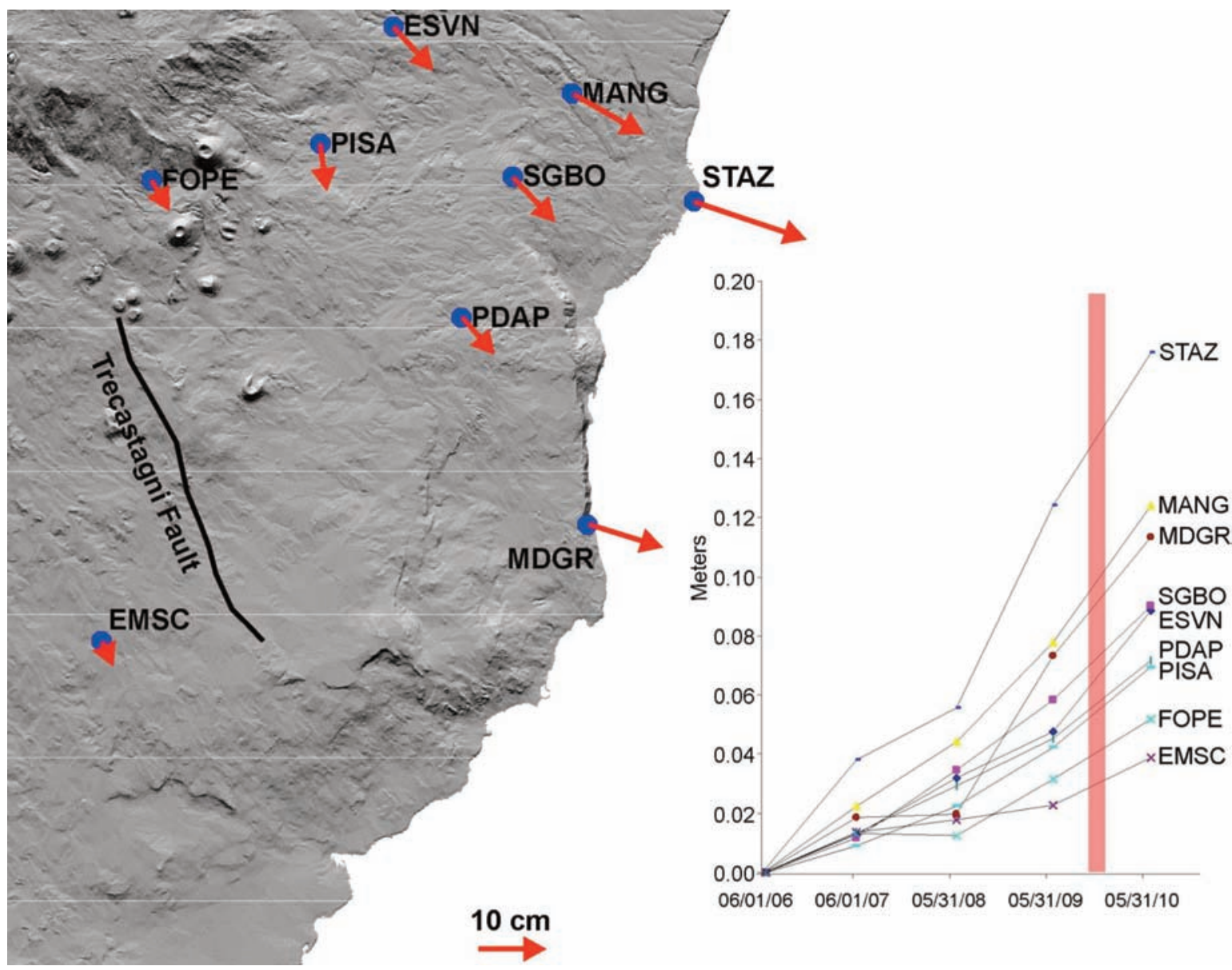

Figure 9. Global positioning system horizontal measurements between June 2006 and June 2010; arrows indicate the amplitude and direction of the displacements, and the graph shows the time series of the displacements. The red bar indicate the October 2009-January 2010 period.

(reservoir inflation, dyke intrusion). The 2008 to 2009 intrusive episode, as well as the 2005 to 2006 inflation phase, appear not to have had any effects on the dynamics of the TF over the entire 2005 to 2010 period.

Future studies, coupled with an improvement in the geophysical monitoring systems close to the TF, should provide new information regarding the TF dynamics and be better able to define how its acceleration (and induced seismicity) are influenced by these different mechanisms proposed.

\section{References}

Aloisi, M., A. Bonaccorso, F. Cannavò, S. Gambino, M. Mattia, G. Puglisi and E. Boschi (2009). A new dyke intrusion style for the Mount Etna May 2008 eruption modelled through continuous tilt and GPS data, Terra Nova, 21, 316-321.

Allard, P., B. Behncke, S. D'Amico, M. Neri and S. Gambino (2006). Mount Etna 1993-2005: Anatomy of an evolving eruptive cycle, Earth Sci. Rev., 78, 85-114.

Azzaro, R. (1999). Earthquake surface faulting at Mount Etna volcano (Sicily) and implications for active tectonics, J. Geodyn., 28, 193-213.

Azzaro R. and S. D'Amico (2008). Catalogo Macrosismico dei
Terremoti Etnei dal 1832 al 2005, INGV-CT, http://www.ct.ingv.it/sismologia/macro.

Bilham, R. and S. Whitehead (1997). Subsurface creep on the Hayward fault, Fremont, Califonia, Geophys. Res. Lett. 24, 1307-1310.

Bonforte A., S. Gambino, F. Guglielmino, F. Obrizzo, M. Palano and G. Puglisi (2007). Ground deformation modelling of flank dynamics prior to the 2002 eruption of Mt. Etna, B. Volcanol., 69, 757-768.

Bonforte, A., A. Bonaccorso, F. Guglielmino, M. Palano, and G. Puglisi (2008). Feeding system and magma storage beneath Mt. Etna as revealed by recent inflation/deflation cycles, J. Geophys. Res., 113, B05406; doi: 10.1029/2007JB005334. Bonforte, A, S. Gambino and M. Neri (2009): Intrusion of eccentric dikes: The case of the 2001 eruption and its role in the dynamics of Mt. Etna volcano, Tectonophysics, 471 (1-2), 78-86.

Bonforte, A., G. Brandi, S. Consoli, G. Falzone, A. Ferro, S. Gambino, F. Guglielmino, G. Laudani, F. Obrizzo and G. Puglisi (2010). The Trecastagni Fault dynamic by using continuous, discrete and satellite ground deformation measurements (Mt. Etna, Italy), EGU General Assembly 2010, Geophysical Research Abstracts Vol. 12, EGU201011479 . 
Bonforte, A., F. Guglielmino, M. Coltelli, A. Ferretti and G. Puglisi (2011). Structural assessment of Mt. Etna volcano from Permanent Scatterers analysis, Geochem. Geophys. Geosyst., 12, Q02002; doi: 10.1029/2010GC003213.

Borgia, A., L. Ferrari and G. Pasquarè (1992). Importance of gravitational spreading in the tectonic and volcanic evolution of Mount Etna, Nature, 357, 231-235.

Froger, J.L., O. Merle and P. Briole (2001). Active speading and regional extension at Mount Etna imaged by SAR interferometry, Earth and Planet. Sc. Lett., 187, 245-258.

Gambino, S. (2004). Continuous dynamic response along a pre-existing structural discontinuity induced by the 2001 eruption at Mt Etna, Earth Planets Space, 56, 447-456.

Hirn, A., A. Nercessian, M. Sapin, F. Ferrucci and G. Wittlinger (1991). Seismic heterogeneity of Mt. Etna: structure and activity, Geophys. J. Int., 105, 139-153.

Hooper, A. (2008). A multi-temporal InSAR method incorporating both persistent scatterer and small baseline approaches, Geophys. Res. Lett., 35, L16302; doi: 10.1029/ 2008GL034654.

Iwatsubo, E.Y., J.W. Ewert and T.L. Murray (1992). Monitoring radial crack deformation by displacement Meters, In: J.W. Ewert and D.A. Swanson (eds.), Monitoring volcanoes: techniques and strategies by the staff of the Cascades observatory, 1980-90, U.S.G.S. Book, pp. 95-101.

Lahr, J.C. (1989). Hypoellipse Version $2.0^{\star}$ : a computer program for determining local earthquake hypocentral parameters, magnitude, and first motion pattern, United States Department of the Survey Menlo Park, California, Open File Report, 89-116.

Lee, J., F. Jeng, H. Chu, J. Angelier and J. Hu (2000). A rodtype creepmeter for measurement of displacement in active fault zone, Earth Planets Space, 52 (5), 321-328.

Lo Giudice, E., and R. Rasà (1992). Very shallow earthquakes and brittle deformation in active volcanic areas: the Etnean region as example, Tectonophys., 202, 257-268.

Neri, M., V. Acocella and B. Behncke (2004). The role of the Pernicana Fault system in the spreading of Mt. Etna (Italy) during the 20022003 eruption, B. Volcanol., 66, 417430; doi: 10.1007 / S00445-003-0322-X.

Neri, M., F. Guglielmino and D. Rust (2007). Flank instability on Mount Etna: Radon, radar interferometry, and geodetic data from the southwestern boundary of the unstable sector, J. Geophys. Res., 112, B04410; doi: 10.1029/2006JB0047.

Peltier, A., T. Staudacher, P. Catherine, L.-P. Ricard, P. Kowalski and P. Bachélery (2006). Subtle precursors of volcanic eruptions at Piton de la Fournaise detected by extensometers, Geophys. Res. Lett., 33, L06315; doi: 10.1029/ 2005 GL 025495.

Puglisi, G., A. Bonforte, A. Ferretti, F. Guglielmino, M. Palano and C. Prati (2008). Dynamics of Mount Etna before, during, and after the July-August 2001 eruption in- ferred from GPS and differential synthetic aperture radar interferometry data, J. Geophys. Res., 113, B06405; doi: 10.1029/2006JB004811.

Richter, C.F. (1958). Elementary Seismology, W. H. Freeman, San Francisco, pp. 135-149.

Solaro, G., V. Acocella, S. Pepe, J. Ruch, M. Neri and E. Sansosti (2010). Anatomy of an unstable volcano from InSAR: Multiple processes affecting flank instability at Mt. Etna, 1994-2008, J. Geophys. Res., 115, B10405; doi: $10.1029 / 2009 J B 000820$.

Walter, T.R., V. Acocella, M. Neri and F. Amelung (2005). Feedback processes between magmatic events and flank movement at Mount Etna (Italy) during the 2002-2003 eruption, J. Geophys. Res., 110, B10205; doi: $10.1029 / 2005$ JB003688.

\footnotetext{
${ }^{\star}$ Corresponding author: Salvatore Gambino, Istituto Nazionale di Geofisica e Vulcanologia, Sezione di Catania, Catania, Italy; email: gambino@ct.ingv.it.

(C) 2011 by the Istituto Nazionale di Geofisica e Vulcanologia. All rights reserved.
} 